\title{
Metabolomic Analysis for Compositional Differences of Bush Tea (Athrixia phylicoides DC.) Subjected to Seasonal Dynamics
}

\author{
Keletso C. Mohale ${ }^{1}\left(\mathbb{D}\right.$, Olusola Bodede ${ }^{1}$, Hintsa T. Araya ${ }^{2} \mathbb{D}$ and Fhatuwani N. Mudau ${ }^{1,3, *}$ \\ 1 Department of Agriculture and Animal Health, College of Agriculture and Environmental Sciences, \\ University of South Africa, Private Bag X6, Florida 1710, South Africa; mohalkc@unisa.ac.za (K.C.M.); \\ Ebodedos@unisa.ac.za (O.B.) \\ 2 ARC-Roodeplaat, Vegetable and Ornamental Plant, Private Bag X293, Pretoria 0001, South Africa; \\ ArayaH@arc.agric.za \\ 3 School of Agricultural, Earth and Environmental Sciences, University of KwaZulu Natal, Scottsville, \\ Pietermaritzburg 3201, South Africa \\ * Correspondence: mudauf@ukzn.ac.za; Tel.: +27-33-260-6076
}

Received: 24 May 2020; Accepted: 19 June 2020; Published: 23 June 2020

\begin{abstract}
Bush tea (Athrixia phylicoides DC.) is a South African indigenous herbal tea rich in secondary metabolites with medicinal significance. However, studies on the effects of seasonal changes on bush tea and quantification of its metabolites using untargeted approach have not been explored. Therefore, this study's objective was to investigate the effects of seasonal variation on the metabolites of bush tea using LC-MS/MS (Liquid Chromatography with Tandem Mass Spectrometry) and ${ }^{1} \mathrm{H}$ NMR (High-Resolution Proton Nuclear Magnetic Resonance) techniques. Bush tea leaves were plucked once in each season namely, autumn (March to May), winter (June to August), spring (September to November), and summer (December to February). The primary metabolites including non-essential amino acids, organic acids, and vitamins in bush tea were predominantly elevated during summer and spring. The ${ }^{1} \mathrm{H}$ NMR-based metabolomic analysis revealed that bush tea metabolome was strongly affected by seasonal variations, using the partial least squares-discriminant analysis (PLS-DA) which demonstrated four distinct groups of seasons. Similarly, the ${ }^{1} \mathrm{H}$ NMR based metabolic profiling of bush tea subjected to different seasons resulted in putative annotation of six phenolic compounds which included rutin, 4-(hydroxyphenyl) propyl coumarate, caffeic acid, hymenoxin, quercetin, and kaempferol. The phenolics and primary metabolites differed remarkably per season with enhanced accumulation observed in the summer and spring harvested bush tea. The LC-MS and ${ }^{1} \mathrm{H}$ NMR metabolomics analysis suggests that summer and spring can be recommended as preferred plucking seasons for bush tea leaves and twigs.
\end{abstract}

Keywords: bush tea; seasonal variation; Athrixia phylicoides; tea metabolites; phenolics

\section{Introduction}

Bush tea (Athrixia phylicoides DC.) is a South African indigenous aromatic and perennial, leafy shrub which has a distinguished history of usage by the native people for decades [1]. Although scientific studies have demonstrated the potential of bush tea as an herbal tea comprising secondary metabolites with beneficial effect and pharmacological properties [2,3], its commercialization is still at its infancy. Bush tea has been reported to contain several polyphenols, sesquiterpenes, coumarins, flavonoids, alkaloids, polysaccharides, amino acids, lipids, vitamins, and inorganic elements [4,5].

Tea metabolome has shown to be influenced by both abiotic and biotic factors [6]. The presence of active compounds and the therapeutic efficacy of tea plants are associated with changing 
climatic conditions resulting from seasonal variations [7,8]. Seasonal fluctuations expose plants to different temperature levels [9], light intensity, and precipitation [6], which affect concentrations of tea phytochemicals and metabolic pathways responsible for the enhancement of metabolites [10]. Environmental factors such as light, influence the biosynthesis of phenolic compounds like catechin in black tea (Camellia sinensis) [6]. Low temperature induced the biosynthesis of catechins [8] while high temperature accelerated leaf growth, diluting the contents of secondary metabolites [9]. Precipitation was found to be negatively associated with the accumulation of all catechin fractions in C. sinensis [6]. In bush tea, Mudau et al. [11] demonstrated seasonal variation effects on selected phytochemicals, reporting that the plant's total antioxidants content were increased during summer and winter, condensed tannins during autumn $(4.82 \%)$, while total polyphenols were increased in winter $\left(51.1 \mathrm{mg} \cdot \mathrm{g}^{-1}\right)$.

Seasonal changes induce different stresses in plants; the thermal stress during warmer seasons enhanced the antioxidant properties and availability of carbohydrates [12], while the solar radiation stress was found to influence the production of phenolic compounds [13]. Consequently, these stresses influence secondary metabolic products of tea plants since they are synthesized under stressful conditions to protect the plant cells from oxidation, protein denaturation, and damage [14]. It is therefore critical to assess teas harvested at different seasons to identify appropriate plucking seasons when the plants have accumulated optimum concentrations of secondary metabolites with pharmaceutical significance $[15,16]$.

Several studies have demonstrated the use metabolomics analysis through proton nuclear magnetic resonance spectroscopy $\left({ }^{1} \mathrm{H}\right.$ NMR) $[17,18]$, gas chromatography-mass spectrometry (GC-MS) [19], and ultra-performance liquid chromatography quadrupole-time of flight mass spectrometry (UPLCQ-TOF MS) in various teas $[20,21]$. These metabolomics studies coupled with chemometrics showed a more comprehensive representation of associations between the environmental factors [20,22,23], growing conditions [24], and tea processing conditions [25] with tea chemical profile. However, data on seasonal effects on metabolites accumulation in bush tea are lacking. The lack of data is accentuated by the fact that bush tea is traditionally picked from the wild. Trials on a small scale are underway since the concept of domesticating wild plant to balance the biodiversity became a norm due to biodiversity laws in many parts of the world. The herbal teas are becoming a thriving business since the demand is exceeding the supply. Hence, the objective of the study was to determine the effects of seasonal changes on the metabolites of bush tea using LC-MS/MS and ${ }^{1} \mathrm{H}$ NMR techniques under cultivated environment.

\section{Materials and Methods}

\subsection{Experimental Site}

The trial was conducted at the Agricultural Research Council, Vegetable and Ornamental Plant Institute, situated about $25 \mathrm{~km}$ north of central Pretoria on the Moloto/KwaMhlanga Road (R573), GPS coordinate $25^{\circ} 59^{\prime \prime} \mathrm{S} ; 28^{\circ} 35^{\prime \prime} \mathrm{E}, 1168 \mathrm{~m}$ altitude. The farm covers approximately $4000 \mathrm{ha}$, of which only 650 ha is under irrigation. The bush tea was grown under $40 \%$ shade net and drip irrigation at a frequency of 3.78 liters per hour for every $15 \mathrm{~s}$ ( 3 times a day) throughout the study.

\subsection{Experimental Design and Treatments}

One-year-old pruned bush tea plants were grown under shade net in three parallel blocks of $11 \mathrm{~m}$. The tea plants were plucked once in each season in a one-year cycle and the seasons included autumn/fall (March to May), winter (June to August), spring (September to November), and summer (December to February). 


\subsection{Sample Preparation}

Mature leaf and twig samples were harvested from bush tea plants and air-dried at room temperature in the shade to constant weight [26] (Samples were then ground to a powder using a benchtop grinder and stored in glass vials below $-50{ }^{\circ} \mathrm{C}$ until extraction.

\subsection{LC-MS/MS Triple Quadrupole Mass Spectrometer}

Fifty milligrams of each sample (five replicates for each treatment) were weighed into a $2 \mathrm{~mL}$ Eppendorf tube. One milliliter of the solvent (75\% LC-MS grade methanol) was added to the samples and vortexed for one minute, and then sonicated for $30 \mathrm{~min}$. Samples were then centrifuged for $15 \mathrm{~min}$ at 10,000 rpm. Seven hundred microliters of the supernatant were then pipetted into HPLC (High Performance Liquid Chromatography) vials, and metal caps with rubber septa were secured with a crimper.

The supernatant was injected into an ultra-high-performance liquid chromatography (UHPLC coupled to a high-resolution triple quadrupole MS (Shimadzu Model 8040, Shimadzu, Kyoto, Japan). Metabolites were separated and detected using ultra C18 AQC column (100 mm $\times 2.1 \mathrm{~mm}$ i.d., $3 \mu \mathrm{m}$ particle) and maintained at $35{ }^{\circ} \mathrm{C}$. The mobile phase consisted of $0.1 \%$ formic acid in water (solvent A) and LC-MS grade methanol (solvent B), at a flow rate of $0.3 \mathrm{~mL} / \mathrm{min}$. Gradient elution applied was: $85 \%$ A: $15 \%$ B to $65 \%$ A: 35\% B in $4 \mathrm{~min}$, changed to $50 \%$ A: $50 \%$ B for 2 min, then to $20 \% \mathrm{~A}: 80 \% \mathrm{~B}$ for $1 \mathrm{~min}$, and back to the initial ratio (85\% A: $15 \%$ B to $65 \% \mathrm{~A}: 35 \% \mathrm{~B})$ for $0.5 \mathrm{~min}$. Furthermore, the UHPLC system was interfaced with a Xevo G2 QT of MS (Shimadzu, Kyoto, Japan), then applied with a source-ESI positive mode; capillary voltage- $3 \mathrm{kV}$; cone voltage $30 \mathrm{~V}$; calibration-sodium formate; lock spray-leucine enkephalin, and mass scan range at 200-1500 m/z. The data acquisition was performed using LabSolutions software LC-MS Ver.5.82 (Shimadzu, Kyoto, Japan) and LabSolutions database.

\section{5. ${ }^{1}$ H NMR Data Acquisition}

Nuclear magnetic resonance spectral data were obtained using a $600 \mathrm{MHz}$ NMR spectrometer (Varian, Inc., Palo Alto, CA, USA), with 20 scans recorded. The sample preparation, data acquisition, analysis, mining, and processing were done as described by Maree and Viljoen [27]. The powdered bush tea samples (50 mg) were weighed into $2 \mathrm{~mL}$ Eppendorf tube for extraction and analysis. A $1.0 \mathrm{~mL}$ solvent mixture of 1:1 methanol D4 and deuterium oxide $\left(\mathrm{D}_{2} \mathrm{O}\right)(\mathrm{pH}$ 6.0) was added. The mixture was vortexed at room temperature for $1 \mathrm{~min}$ and ultra-sonicated for $15 \mathrm{~min}$ to break the cell membranes, and then centrifuged for $5 \mathrm{~min}$. Approximately $0.5 \mathrm{~mL}$ of the supernatant was transferred into NMR tubes for analysis.

All ${ }^{1} \mathrm{H}$ spectra were subjected to baseline and phase correction using MestReNova 12.0 (Mestrelab Research S.L., Santiago de Compostela, Spain). The spectral regions (0-10.00 ppm) were divided into 0.04 ppm bins, converted to American Standard Code for Information Interchange (ASCII) format and imported to Microsoft ${ }^{\circledR}$ Excel 2010 (Microsoft Corporation, Redmond, Washington). MetaboAnalyst with Pareto scaling method was used to perform the multivariate data analysis.

\subsection{Statistical Analysis}

Data were subjected to one-way analysis of variance (ANOVA), carried out using STATISTICA (StaSoft Inc., Tulsa, OK, USA) package (2011) to analyze the integrated peak area. Mean separation was done using Tukey's Honest Significant Difference (HSD) at $p<0.05$. The supervised partial least squaresdiscriminant analysis (PLS-DA) was carried out using MetaboAnalyst 4.0 (http://metaboanalyst.ca). The heatmap was constructed using hierarchical cluster analysis (Euclidean distance and clustering algorithms as Ward's linkage) in MetaboAnalyst software. 


\section{Results}

\subsection{Seasonal Variation on Bush Tea Primary Metabolites Using LC-MS/MS}

The heatmap revealed distinct groups of primary metabolites of bush tea harvested at different seasons indicating that tea metabolome patterns are dependent on seasonal changes. The heatmap comprises of two main clusters with the second cluster further divided into two. Bush tea harvested in summer grouped in the first cluster on the left. The second cluster was divided into two groups, and the autumn and winter plucked bush tea gathered together in one sub-cluster while spring plucked bush tea clustered and dominated the sub-cluster on the right (Figure 1).

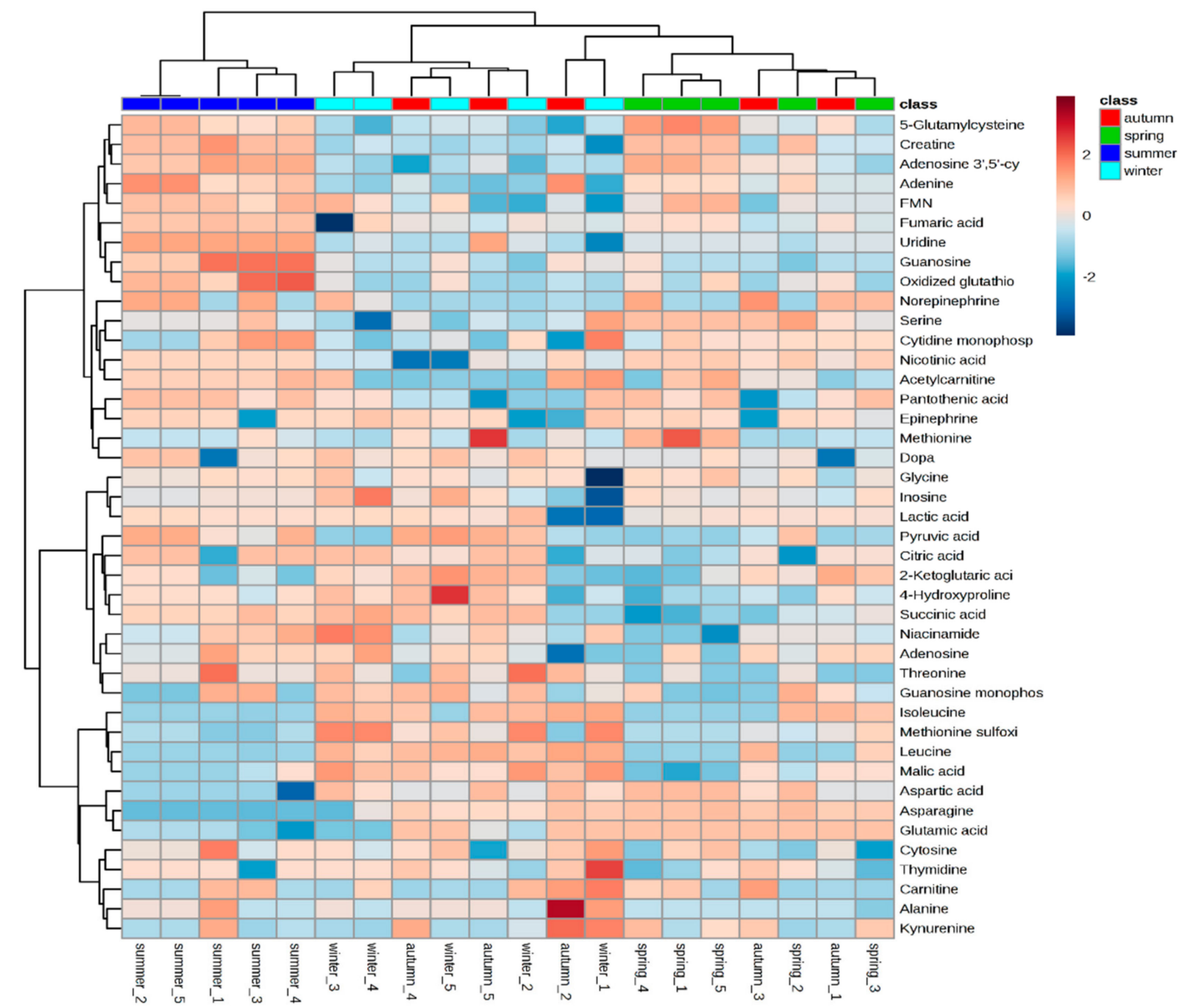

Figure 1. The heatmap for seasonal variation of bush tea primary metabolites identified from LC-MS/MS (Liquid Chromatography with Tandem Mass Spectrometry) triple quadrupole on bush tea (A. phylicoides DC.) using unsupervised hierarchical clustering. The row represents the primary metabolites and column represent seasons.

The LC-MS/MS Triple Quadrupole detected different groups of primary metabolites and statistical analysis of their integrated peak revealed significant differences among the seasons (Table 1). For essential amino acids, the summer harvested bush tea samples significantly exhibited the highest threonine peak area $\left(8.73 \times 10^{5}\right)$, and the lowest area was recorded in the autumn bush tea plants with $3.29 \times 10^{5}$ peak area. Harvested leaves and twigs exhibited higher methionine sulfoxide in winter $\left(2.80 \times 10^{5}\right)$ and low in autumn $\left(1.45 \times 10^{5}\right)$. Both leucine and isoleucine were high in the winter and low in the summer bush tea leaves and twigs. 
Table 1. Effects of seasonal variations on peak intensities of primary metabolites from bush tea (A. phylicoides DC.)

\begin{tabular}{|c|c|c|c|c|}
\hline Season & Autumn & Winter & Spring & Summer \\
\hline & \multicolumn{4}{|c|}{ (Peak Intensities) } \\
\hline \multicolumn{5}{|l|}{ Essential amino acids } \\
\hline Threonine & $3.29 \times 10^{5} \pm 0.42 \times 10^{5} \mathrm{~b}$ & $3.83 \times 10^{5} \pm 0.75 \times 10^{5} \mathrm{~b}$ & $8.73 \times 10^{5} \pm 1.34 \times 10^{5} \mathrm{a}$ & $8.65 \times 10^{5} \pm 0.41 \times 10^{5} \mathrm{a}$ \\
\hline Methionine sulfoxide & $1.45 \times 10^{5} \pm 0.28 \times 10^{5} \mathrm{c}$ & $2.80 \times 10^{5} \pm 0.47 \times 10^{5} a$ & $2.20 \times 10^{5} \pm 0.13 \times 10^{5} \mathrm{~b}$ & $1.54 \times 10^{5} \pm 0.07 \times 10^{5} \mathrm{c}$ \\
\hline Isoleucine & $3.24 \times 10^{4} \pm 1.13 \times 10^{4} \mathrm{a}$ & $3.58 \times 10^{4} \pm 0.93 \times 10^{4} \mathrm{a}$ & $2.01 \times 10^{4} \pm 0.13 \times 10^{4} \mathrm{~b}$ & $0.0 \pm 0.0 \mathrm{c}$ \\
\hline Leucine & $3.49 \times 10^{4} \pm 1.28 \times 10^{4} \mathrm{~b}$ & $3.85 \times 10^{4} \pm 0.39 \times 10^{4} \mathrm{a}$ & $0.59 \times 10^{4} \pm 0.04 \times 10^{4} \mathrm{c}$ & $0.0 \pm 0.0 \mathrm{~d}$ \\
\hline \multicolumn{5}{|c|}{ Conditional and non-essential amino acids } \\
\hline Aspartic acid & $1.46 \times 10^{5} \pm 0.19 \times 10^{5} \mathrm{bc}$ & $1.27 \times 10^{5} \pm 012 \times 10^{5} \mathrm{c}$ & $3.23 \times 10^{5} \pm 0.43 \times 10^{5} \mathrm{a}$ & $1.65 \times 10^{5} \pm 0.09 \times 10^{5} \mathrm{~b}$ \\
\hline Serine & $1.46 \times 10^{5} \pm 0.21 \times 10^{5} \mathrm{c}$ & $0.99 \times 10^{5} \pm 0.09 \times 10^{5} \mathrm{~d}$ & $3.82 \times 10^{5} \pm 0.41 \times 10^{5} a$ & $2.06 \times 10^{5} \pm 0.12 \times 10^{5} \mathrm{~b}$ \\
\hline Alanine & $5.16 \times 10^{5} \pm 0.77 \times 10^{5} \mathrm{c}$ & $4.42 \times 10^{5} \pm 0.61 \times 10^{5} c$ & $9.91 \times 10^{5} \pm 1.34 \times 10^{5} \mathrm{~b}$ & $11.93 \times 10^{5} \pm 2.47 \times 10^{5} \mathrm{a}$ \\
\hline Glutamic acid & $1.42 \times 10^{6} \pm 0.21 \times 10^{6} \mathrm{c}$ & $1.32 \times 10^{6} \pm 0.16 \times 10^{6} c$ & $2.46 \times 10^{6} \pm 0.27 \times 10^{6} a$ & $1.69 \times 10^{6} \pm 0.14 \times 10^{6} \mathrm{~b}$ \\
\hline Glycine & $0.99 \times 10^{4} \pm 0.09 \times 10^{4} \mathrm{c}$ & $1.16 \times 10^{4} \pm 0.34 \times 10^{4} c$ & $2.57 \times 10^{4} \pm 0.29 \times 10^{4} \mathrm{a}$ & $1.63 \times 10^{4} \pm 0.58 \times 10^{4} \mathrm{~b}$ \\
\hline Proline & $3.48 \times 10^{7} \pm 0.07 \times 10^{7} \mathrm{~b}$ & $2.75 \times 10^{7} \pm 0.47 \times 10^{7} c$ & $10.99 \times 10^{7} \pm 1.69 \times 10^{7} a$ & $9.87 \times 10^{7} \pm 0.56 \times 10^{7} \mathrm{a}$ \\
\hline Citric acid & $14.22 \times 10^{4} \pm 4.85 \times 10^{5} \mathrm{c}$ & $22.34 \times 10^{5} \pm 6.45 \times 10^{5} \mathrm{~b}$ & $15.41 \times 10^{5} \pm 2.52 \times 10^{5} \mathrm{c}$ & $36.27 \times 10^{5} \pm 7.59 \times 10^{5} a$ \\
\hline Succinic acid & $2.78 \times 10^{4} \pm 0.83 \times 10^{4} \mathrm{c}$ & $4.04 \times 10^{4} \pm 1.28 \times 10^{4} \mathrm{~b}$ & $2.69 \times 10^{4} \pm 0.23 \times 10^{4} c$ & $5.62 \times 10^{4} \pm 0.35 \times 10^{4} \mathrm{a}$ \\
\hline $\begin{array}{c}\text { Fumaric acid } \\
\text { Vitamins }\end{array}$ & $4.20 \times 10^{4} \pm 1.33 \times 10^{4} \mathrm{c}$ & $4.65 \times 10^{4} \pm 2.19 \times 10^{4} \mathrm{c}$ & $10.03 \times 10^{4} \pm 2.38 \times 10^{4} \mathrm{~b}$ & $20.97 \times 10^{4} \pm 1.32 \times 10^{4} a$ \\
\hline Nicotinic acid & $1.98 \times 10^{4} \pm 0.56 \times 10^{4} \mathrm{~b}$ & $1.21 \times 10^{4} \pm 0.46 \times 10^{4} \mathrm{c}$ & $9.25 \times 10^{4} \pm 1.51 \times 10^{4} \mathrm{a}$ & $8.60 \times 10^{4} \pm 0.65 \times 10^{4} a$ \\
\hline Niacin amide & $6.84 \times 10^{4} \pm 1.49 \times 10^{4} \mathrm{c}$ & $9.54 \times 10^{4} \pm 1.86 \times 10^{4} \mathrm{~b}$ & $9.49 \times 10^{4} \pm 0.84 \times 10^{4} \mathrm{~b}$ & $15.00 \times 10^{4} \pm 1.65 \times 10^{4} a$ \\
\hline Pantothenic acid & $2.19 \times 10^{4} \pm 0.41 \times 10^{4} \mathrm{c}$ & $2.91 \times 10^{4} \pm 0.69 \times 10^{4} \mathrm{~b}$ & $6.92 \times 10^{4} \pm 1.21 \times 10^{4} \mathrm{a}$ & $6.74 \times 10^{4} \pm 0.57 \times 10^{4} a$ \\
\hline
\end{tabular}

Values are means \pm standard errors. Means in the same row with different letters are significantly $(p<0.05)$ different using Tukey's Honest Significant Test. 
Non-essential amino acids were also evaluated for their accumulation in each season (Table 1). The spring harvested bush tea samples showed high integrated peak area of asparagine $\left(1.51 \times 10^{6}\right)$ while summer exhibited low peak area (0.0). The intensity of aspartic acid was high in the spring $\left(3.23 \times 10^{5}\right)$, followed by summer $\left(1.65 \times 10^{5}\right)$ and autumn $\left(1.46 \times 10^{5}\right)$ bush tea plants, and low in the winter $\left(1.27 \times 10^{5}\right)$ harvested tea plants. A similar trend was observed with compound serine. Alanine was found to be high in the summer $\left(11.93 \times 10^{5}\right)$, followed by spring $\left(9.91 \times 10^{5}\right)$, then autumn $\left(5.16 \times 10^{5}\right)$ and low area under peak were recorded in the winter samples $\left(4.42 \times 10^{5}\right)$.

The conditional amino acids were also evaluated, and the high peak area of glutamic acid was recorded in the spring samples with $2.46 \times 10^{6}$ and low in the winter harvested bush tea samples with $1.32 \times 10^{6}$. Bush tea harvested during spring exhibited high peak area of glycine $\left(2.57 \times 10^{4}\right)$ while low peak area $\left(0.99 \times 10^{3}\right)$ was detected in the autumn sampled plants. Proline area under peak was high in the spring samples with $10.99 \times 10^{7}$ and low in the winter samples with $2.75 \times 10^{7}$.

Malic acid was high in winter with the peak area of $13.95 \times 10^{5}$ and low in the autumn bush tea leaves and twigs with rea of $7.72 \times 10^{5}$. A similar trend was observed on pyruvic acid, lactic acid, citric acid, fumaric acid and succinic acid, where all the mentioned organic acids were high in summer and low in autumn.

Nicotinic acid, also known as vitamin $\mathrm{B}_{3}$ showed high peak area in spring, followed by summer and autumn but low in autumn. Niacinamide (NAA), another form of vitamin $\mathrm{B}_{3}$, was high in the summer samples $\left(15.00 \times 10^{4}\right)$ and low in the winter bush tea samples $\left(6.84 \times 10^{4}\right)$. The high intensity of pantothenic acid (vitamin $B_{5}$ ) was detected in the spring plucked leaves and twigs $\left(6.92 \times 10^{4}\right)$ low area under peak was recorded in the autumn $\left(2.19 \times 10^{4}\right)$ (Table 1$)$.

\subsection{The Effect of Harvest Season on Bush Tea Metabolome Using ${ }^{1} H N M R$}

The ${ }^{1} \mathrm{H}$ NMR metabolites peak intensities of bush tea harvested in four different seasons (autumn, winter, spring, and summer) were clearly distinguished using a co-variance of data the PLS-DA (Figure 2). The seasons differentiated from each other on the first two-component PLS-DA scores plot by the principal component $t(1)$ (70.9\%), principal component $t(2)(2.8 \%)$, and principal component $t(3)$ $(13.9 \%)$. The PLS-DA revealed four distinct groups, bush tea harvested in winter grouped at the top towards the right side of the PLS-DA score plot while the autumn plucked bush tea aligned together towards the right. The summer harvested bush tea clustered together in the middle of the PLS-DA score plot while the spring plucked grouped toward the bottom right side.

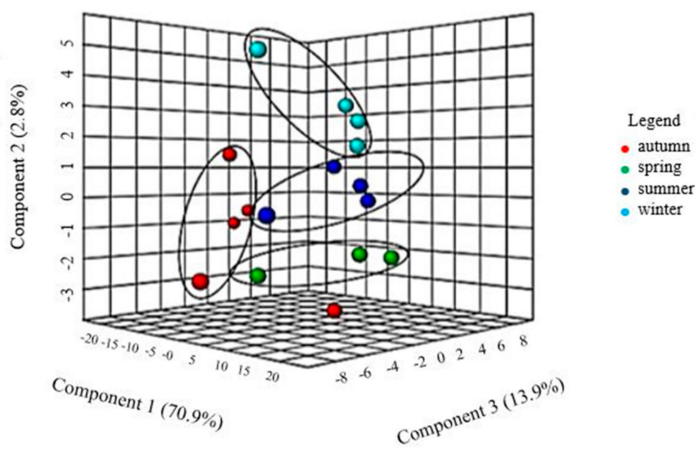

Figure 2. Partial least squares-discriminant analysis (PLS-DA) component score plot for ${ }^{1} \mathrm{H}$ NMR (High-Resolution Proton Nuclear Magnetic Resonance) peak intensities of 20 bush tea (A. phylicoides DC.) samples subjected to seasonal variation.

\subsection{Annotation of Bush Tea Metabolites from ${ }^{1} \mathrm{H}$ NMR Spectrum}

Figure 3 presents representative one dimensional ${ }^{1} \mathrm{H}$ NMR fingerprints of bush tea samples collected over four seasons. The spectra allow for the annotation of phenolic compounds 1-6 upon the comparison of their respective chemical shifts with literature values. The annotated compounds 
included rutin with peaks at $\delta_{\mathrm{H}} 7.64,6.38,6.18,3.34$, and $3.82 \mathrm{ppm}$ (rutinose sugar peaks) and $1.06 \mathrm{ppm}$ (rhamnose- $\mathrm{CH}_{3}$ ), which was supported with the anomeric protons observed as doublets at $\delta_{\mathrm{H}} 4.55$ and $5.09 \mathrm{ppm}[28,29]$. Peaks corresponding to (4-hydroxyphenyl) propyl coumarate $\left(\delta_{\mathrm{H}} 7.54(\mathrm{~J}=15.9 \mathrm{~Hz})\right.$, $7.51,6.76,6.68,6.32(J=15.9 \mathrm{~Hz}), 4.08,2.69$, and $2.01 \mathrm{ppm})$ [30] and caffeic acid $(7.62 \mathrm{ppm}(\mathrm{J}=15.78 \mathrm{~Hz})$, $7.03,6.99,6.92$, and $6.38 \mathrm{ppm}(J=15.78 \mathrm{~Hz})$ [31] were also observed. In addition, the polymethoxylated flavone, hymenoxin $\left(\delta_{\mathrm{H}} 7.59,7.44,7.06,6.60,4.05,4.02,3.99\right.$, and $\left.3.97 \mathrm{ppm}\right)$ [32], quercetin $(7.66,7.54$, $6.88,6.41$, and $6.20 \mathrm{ppm})$ [33] and kaempferol $(8.08,6.92,6.45$, and $6.19 \mathrm{ppm})$ were also identified [34]. The strong doublet at $5.41(\mathrm{~J}=3.84 \mathrm{~Hz})$ is characteristic of sucrose while the upfield resonance around $\delta_{\mathrm{H}} 0.87$ is characteristic of the terminal methyl groups of fatty acids. This is further supported by $\delta_{\mathrm{H}}$ $1.25,1.30 \mathrm{ppm}$ which are assignable to repeating methylene and $\delta_{\mathrm{H}} 2.00 \mathrm{ppm}$ for allylic methylene units of the fatty acids $[35,36]$.
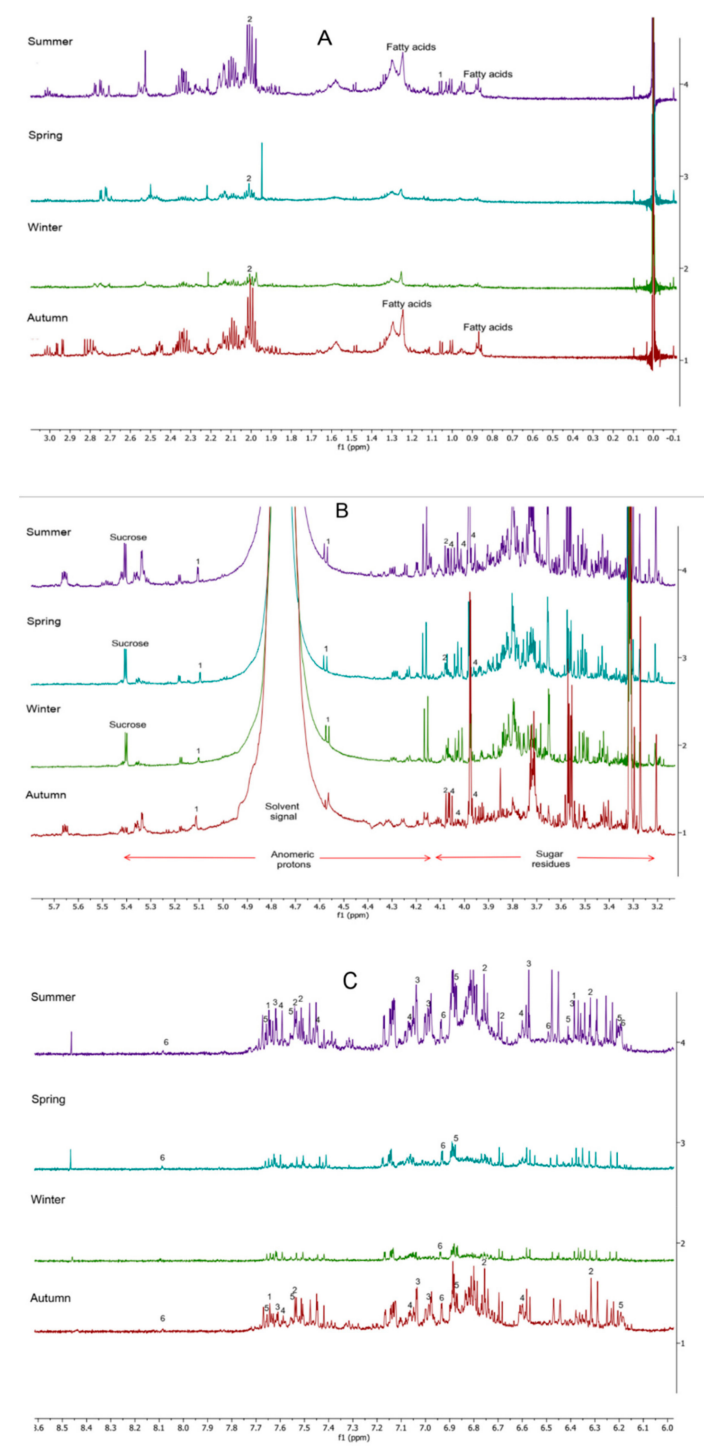

Figure 3. $(\mathrm{A}-\mathrm{C}){ }^{1} \mathrm{H}$ NMR spectra $(600 \mathrm{MHz}$; TSP $=0.00 \mathrm{ppm})$ of bush tea harvested in four seasons showing annotated compounds: (1) rutin, (2) (4-hydroxyphenyl) propyl coumarate, (3) hymenoxin, (4) caffeic acid, (5) quercetin, (6) kaempferol, sucrose, and fatty acids.

To evaluate seasonal variations of the selected compounds, characteristic chemical shifts of compounds were selectively plotted against their respective intensities (Figure 4), due to overlaps in the basic resonances of the phenolic protons and those of the coumaric acid derivatives. 


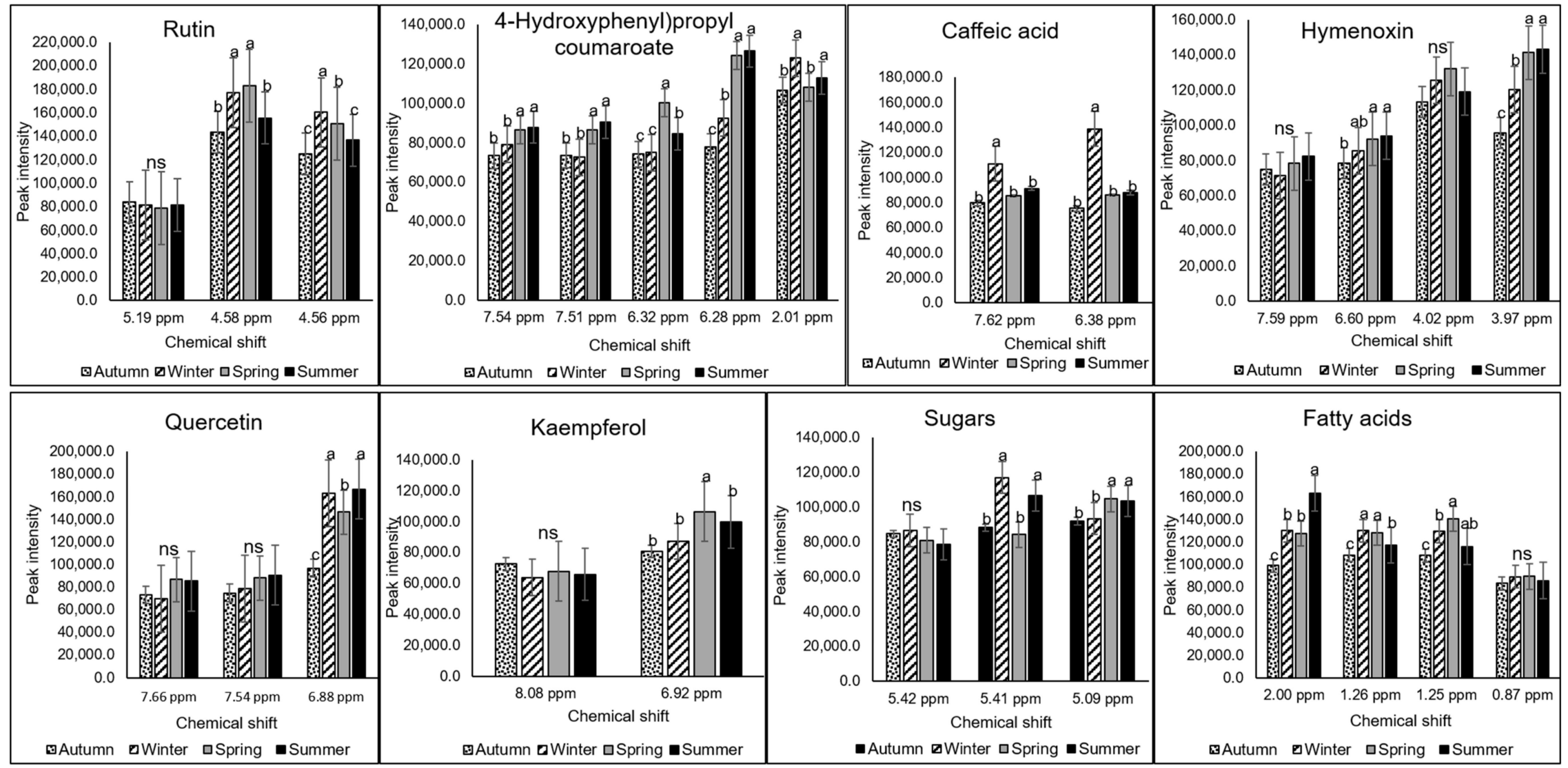

Figure 4. The effect of season on peak intensities of compounds annotated from bush tea. Peak intensity values per chemical shift with the same letters are not significantly different at $p \leq 0.05$ using Tukey's Honest Significant Test, ns = non-significant. The error bars on the figure represent mean standard error 


\section{Discussion}

Determination of the best harvesting periods or seasons yielding maximum concentrations of phytochemicals is fundamental for improved tea quality. Data that compares seasonal responses on metabolites in bush tea is lacking. Hence, this study investigated the dependence of bush tea metabolites on seasonal changes through metabolomics approach and found differences in the accumulation of various metabolites in each season. The essential amino acids were highly accumulated in the winter harvested bush tea. This could be attributed to the acclimation of tea plants to cold winter season as a mechanism for cold tolerance. The synthesis of proteins (conditional and non-essential amino acids) were favored by spring conditions while the production of organic acids and vitamins (vitamin $B_{3}$ and $B_{5}$ ) in bush tea plants were enhanced by summer conditions. Thermal stress, known to influence metabolic regulation $[37,38]$, could be responsible for higher proteins and vitamins during spring and summer season.

The ${ }^{1} \mathrm{H}$ NMR-based metabolomics method is a convenient means to explore the link between tea metabolome and climatic variables [24]. Hence, there was a need to ascertain the metabolic dependence of bush tea on seasonal dynamics through the ${ }^{1} \mathrm{H}$ NMR chemometrics data analysis. The strong dependence of bush tea on seasons were illustrated in the PLS-DA and the heatmap. The changing phytochemical pattern in tea plants is based on the metabolic regulation within the cell, which is affected by many factors, including temperature and water.

The annotated phenolic compounds namely rutin, (4-hydroxyphenyl) propyl coumarate, caffeic acid, quercetin, kaempferol, and hymenoxin have been previously isolated from bush tea extracts $[2,3,30]$. Therefore, this study provides a novel discovery of how each of the select compounds is affected by seasonal dynamics to understand the picking windows of bush tea in South Africa.

The selected phenolic peaks of bush tea flavonols (rutin, kaempferol, and quercetin) were significantly influenced by seasonal changes (Figure 4). Rutin and quercetin were elevated in summer while kaempferol was increased in spring. The biosynthesis of these phenolic compounds in summer harvested bush tea leaves could be induced by warmer temperatures, stronger sunlight, and longer daytime length $[9,39]$. Hence, the autumn and winter harvested bush tea recorded low intensities of rutin, kaempferol, and quercetin.

The leaves and twigs of bush tea plucked in winter, which is a slow-growing or dormant period had higher intensity of caffeic acid and lower in autumn. The cold stress during winter might have effectively stimulated the production of this phenolic compound in tea plant cells [14]. Hence, there was a significant increase during the lower temperature season. This is consistent with findings by Król et al. [40] who reported an increased caffeic acid in grapevine under cold stress. The intensities of 4-(Hydroxyphenyl) propyl coumarate were elevated in the summer plucked bush tea leaves and twigs and reduced in the autumn harvested bush tea. Accumulation of this coumarate during summer may be attributed to the higher precipitation levels and warmer temperatures which are known to enhance induction of the biosynthesis of total phenolics [41]. Hymenoxin was increased in the spring plucked bush tea leaves and twigs and reduced in autumn. In the experimental site, spring climatic conditions are also characterized by warm to hot temperature and low to high rainfall levels and day length, thus, the accumulation of hymenoxin in this season could be a result of precipitation and sunlight exposure which is associated with elevation of concentration of phenolic compounds [42].

Seasonal comparison of the ${ }^{1} \mathrm{H}$ NMR chemical shifts peak intensities of the sugars and fatty acids were also analyzed statistically. Generally, fatty acids were higher in the spring and summer plucked bush tea leaves and lower in the autumn plucked bush tea leaves. Our study suggests that summer and spring enhanced primary and secondary metabolites, and this is consistent with previous studies which recommended summer as the best season for enhanced total antioxidants [11] and polyphenolic content [43]. 


\section{Conclusions}

The study demonstrated that changes in the chemical profile pattern of bush tea are associated with seasonal variations influenced by climatic conditions in each season. Concentrations of non-essential amino acids, organic acids and vitamins in bush tea were increased in summer and spring, respectively. The PLS-DA further confirmed the dependence bush teas secondary metabolites on seasons. The six phenolic compounds annotated in this study include rutin, 4-(hydroxyphenyl) propyl coumarate, caffeic acid, hymenoxin, quercetin, and kaempferol. The intensities of the selected phenolics, sugars and fatty acids varied significantly per season with higher intensities in the summer and spring plucked bush tea leaves and twigs. Based on the LC-MS and ${ }^{1} \mathrm{H}$ NMR metabolomics analysis, summer and spring can be recommended as preferred plucking seasons for bush tea leaves and twigs. A further study is, however, recommended to quantitatively determine the seasonal variation of the full spectrum of the bush tea compounds.

Author Contributions: Conceptualization, F.N.M. and H.T.A.; data curation, K.C.M., and O.B.; formal analysis, K.C.M., and O.B.; funding acquisition, F.N.M.; investigation, K.C.M.; methodology, K.C.M., and O.B.; resources, H.T.A., and F.N.M.; supervision, F.N.M.; writing-original draft, K.C.M.; writing-review \& editing, K.C.M.; O.B., H.T.A., and F.N.M. All authors have read and agreed to the published version of the manuscript.

Funding: This research was funded by the University of South Africa, Agriculture and Animal Health Departmental operation funds GUN number 200100.

Acknowledgments: The authors would like to thank the Agricultural Research Council-VOPI for their technical support and facilities.

Conflicts of Interest: The authors declare no conflict of interest.

\section{References}

1. Nchabeleng, L.; Mariga, I.K.; Ngezimana, W.; Mudau, F.N. Bush tea (Athrixia phylicoides DC.) success stories in South Africa: A review. ESci. J. Crop Prod. 2013, 2, 37-43.

2. McGaw, L.J.; Bagla, V.; Steenkamp, P.A.; Fouche, G.; Olivier, J.; Eloff, J.N.; Myer, M.S. Antifungal and antibacterial activity and chemical composition of polar and non-polar extracts of Athrixia phylicoides determined using bioautography and HPLC. BMC Complement. Altern. Med. 2013, 13, 356. [CrossRef] [PubMed]

3. Malongane, F.; McGaw, L.J.; Nyoni, H.; Mudau, F. Metabolic profiling of four South African herbal teas using high resolution liquid chromatography-mass spectrometry and nuclear magnetic resonance. Food Chem. 2018, 257, 90-100. [CrossRef]

4. Lerotholi, L.; Chaudhary, S.; Combrinck, S.; Viljoen, A.M. Bush tea (Athrixia phylicoides): A review of the traditional uses, bioactivity and phytochemistry. South Afr. J. Bot. 2017, 110, 4-17. [CrossRef]

5. Tshivhandekano, I.; Ntushelo, K.; Ngezimana, W.; Tshikalange, T.E.; Mudau, F. Chemical compositions and antimicrobial activities of Athrixia phylicoides DC. (bush tea), Monsonia burkeana (special tea) and synergistic effects of both combined herbal teas. Asian Pac. J. Trop. Med. 2014, 7, 448-453. [CrossRef]

6. Wang, Y.; Gao, L.; Shan, Y.; Liu, Y.; Tian, Y.; Xia, T. Influence of shade on flavonoid biosynthesis in tea (Camellia sinensis (L.) O. Kuntze). Sci. Hortic. 2012, 141, 7-16. [CrossRef]

7. Mudau, F.N.; Ngele, A.; Mashela, P.W.; Soundy, P. Seasonal variation of tannin content in wild bush tea. Med. Aromat. Plant Sci. Biotechnol. 2007, 1,74-76.

8. Wei, K.; Wang, L.; Zhou, J.; He, W.; Zeng, J.-M.; Jiang, Y.-W.; Cheng, H. Comparison of catechins and purine alkaloids in albino and normal green tea cultivars (Camellia sinensis L.) by HPLC. Food Chem. 2012, 130, 720-724. [CrossRef]

9. Yao, L.; Caffin, N.; D’Arcy, B.; Jiang, Y.; Shi, J.; Singanusong, R.; Liu, X.; Datta, N.; Kakuda, Y.; Xu, Y. Seasonal Variations of Phenolic Compounds in Australia-Grown Tea (Camellia sinensis). J. Agric. Food Chem. 2005, 53, 6477-6483. [CrossRef]

10. Selmar, D.; Kleinwächter, M. Stress Enhances the Synthesis of Secondary Plant Products: The Impact of Stress-Related Over-Reduction on the Accumulation of Natural Products. Plant Cell Physiol. 2013, 54, 817-826. [CrossRef] 
11. Mudau, F.; Mogotlane, I.; Mashela, P.; Soundy, P. Seasonal Variation of Total Antioxidant Contents of Wild Bush Tea. Acta Hortic. 2008, 802, 273-276. [CrossRef]

12. Morison, J.I.L.; Lawlor, D.W. Interactions between increasing CO2concentration and temperature on plant growth. Plant Cell Environ. 1999, 22, 659-682. [CrossRef]

13. Grace, S.C.; Logan, B.A. Energy dissipation and radical scavenging by the plant phenylpropanoid pathway. Philos. Trans. R. Soc. B Boil. Sci. 2000, 355, 1499-1510. [CrossRef] [PubMed]

14. Kranner, I.; Beckett, R.; Wornik, S.; Zorn, M.; Pfeifhofer, H.W. Revival of a resurrection plant correlates with its antioxidant status. Plant J. 2002, 31, 13-24. [CrossRef] [PubMed]

15. Kale, V.S. Variable rates of primary and secondary metabolites during different seasons and physiological stages in Convolvulus, Withania and Datura. Asian J. Exp. Biol. Sci. 2010, 10, 50-53.

16. Szakiel, A.; Paczkowski, C.; Henry, M. Influence of environmental abiotic factors on the content of saponins in plants. Phytochem. Rev. 2010, 10, 471-491. [CrossRef]

17. Lee, J.-E.; Lee, B.-J.; Hwang, J.-A.; Ko, K.-S.; Chung, J.-O.; Kim, E.-H.; Lee, S.-J.; Hong, Y.-S. Metabolic Dependence of Green Tea on Plucking Positions Revisited: A Metabolomic Study. J. Agric. Food Chem. 2011, 59, 10579-10585. [CrossRef]

18. Kellogg, J.J.; Graf, T.; Paine, M.F.; McCune, J.S.; Kvalheim, O.M.; Oberlies, N.H.; Cech, N.B. Comparison of Metabolomics Approaches for Evaluating the Variability of Complex Botanical Preparations: Green Tea (Camellia sinensis) as a Case Study. J. Nat. Prod. 2017, 80, 1457-1466. [CrossRef]

19. Vuwani, M.K.; Nkomo, M.; Ngezimana, W.; Makunga, N.P.; Mudau, F. Response of Phytochemicals in Bush Tea (Athrixia phylicoides DC.) as Influenced by Selected Micronutrients. HortScience 2017, 52, 965-971. [CrossRef]

20. Zhang, Q.; Shi, Y.; Ma, L.; Yi, X.; Ruan, J. Metabolomic Analysis Using Ultra-Performance Liquid Chromatography-Quadrupole-Time of Flight Mass Spectrometry (UPLC-Q-TOF MS) Uncovers the Effects of Light Intensity and Temperature under Shading Treatments on the Metabolites in Tea. PLoS ONE 2014, 9, e112572. [CrossRef]

21. Jing, J.; Shi, Y.-Z.; Zhang, Q.; Wang, J.; Ruan, J. Prediction of Chinese green tea ranking by metabolite profiling using ultra-performance liquid chromatography-quadrupole time-of-flight mass spectrometry (UPLC-Q-TOF/MS). Food Chem. 2017, 221, 311-316. [CrossRef] [PubMed]

22. Chen, Y.; Jiang, Y.; Duan, J.; Shi, J.; Xue, S.; Kakuda, Y. Variation in catechin contents in relation to quality of 'Huang Zhi Xiang' Oolong tea (Camellia sinensis) at various growing altitudes and seasons. Food Chem. 2010, 119, 648-652. [CrossRef]

23. Lee, J.-E.; Lee, B.-J.; Chung, J.-O.; Hwang, J.-A.; Lee, S.-J.; Lee, C.-H.; Hong, Y.-S. Geographical and Climatic Dependencies of Green Tea (Camellia sinensis) Metabolites: A1H NMR-Based Metabolomics Study. J. Agric. Food Chem. 2010, 58, 10582-10589. [CrossRef]

24. Lee, J.-E.; Lee, B.-J.; Chung, J.-O.; Kim, H.-N.; Kim, E.; Jung, S.; Lee, H.; Lee, S.-J.; Hong, Y.-S. Metabolomic unveiling of a diverse range of green tea (Camellia sinensis) metabolites dependent on geography. Food Chem. 2015, 174, 452-459. [CrossRef] [PubMed]

25. Tan, J.; Dai, W.; Lu, M.; Lv, H.; Guo, L.; Zhang, Y.; Zhu, Y.; Peng, Q.; Lin, Z. Study of the dynamic changes in the non-volatile chemical constituents of black tea during fermentation processing by a non-targeted metabolomics approach. Food Res. Int. 2016, 79, 106-113. [CrossRef]

26. Mudau, F.N.; Ngezimana, W. Effect of different drying methods on chemical composition and antimicrobial activity of bush tea (Athrixia phylicoides). Int. J. Agric. Biol. 2014, 16, 1011-1014.

27. Maree, J.; Viljoen, A.M. Phytochemical distinction between Pelargonium sidoides and Pelargonium reniforme-A quality control perspective. South Afr. J. Bot. 2012, 82, 83-91. [CrossRef]

28. Selvaraj, K.; Chowdhury, R.; Bhattacharjee, C. Isolation and structural elucidation of flavonoids from aquatic fern Azolla microphylla and evaluation of free radical scavenging activity. Int. J. Pharm. Pharm. Sci. 2013, 5, 743-749.

29. Georgeta SPana, P.I.; Tunde, H.; Sanda, B. The isolation and identification of rutin from pharmaceutical products. Analele Univ. Din. Oradea Fasc. Ecotoxicol. Zooteh Si Tehnol. Ind. Aliment. 2016, 16, 109-113.

30. Padayachee, K. The Phytochemistry and Biological Activities of Athrixia Phylicoides. M.Sc. Thesis, University of Witwatersrand, Johannesburg, South Africa, 2011. Available online: http://wiredspace.wits.ac.za/handle/ 10539/10667 (accessed on 11 August 2017). 
31. Exarchou, V.; Troganis, A.; Gerothanassis, I.P.; Tsimidou, M.Z.; Boskou, D. Identification and quantification of caffeic and rosmarinic acid in complex plant extracts by the use of variable-temperature two-dimensional nuclear magnetic resonance spectroscopy. J. Agric. Food Chem. 2001, 49, 2-8. [CrossRef]

32. Hayashi, T.; Uchida, K.; Hayashi, K.; Niwayama, S.; Morita, N. A cytotoxic flavone from Scoparia dulcis L. Chem. Pharm. Bull. 1988, 36, 4849-4851. [CrossRef]

33. Sambandam, B.; Thiyagarajan, D.; Ayyaswamy, A.; Raman, P.; Kulasekaran, J.; Venkatasamy, H. Extraction and isolation of flavonoid quercetin from the leaves of Trigonella foenum-graecum and their anti-oxidant activity. Int. J. Pharm. Pharm. Sci. 2016, 8, 120-124.

34. Lin, L.-J.; Huang, X.-B.; Lv, Z.-C. Isolation and identification of flavonoids components from Pteris vittata L. SpringerPlus 2016, 5, 1649. [CrossRef] [PubMed]

35. Caligiani, A.; Palla, G.; Maietti, A.; Cirlini, M.; Brandolini, V. 1H NMR Fingerprinting of Soybean Extracts, with Emphasis on Identification and Quantification of Isoflavones. Nutrients 2010, 2, 280-289. [CrossRef] [PubMed]

36. Gogna, N.; Hamid, N.; Dorai, K. Metabolomic profiling of the phytomedicinal constituents of Carica papaya L. leaves and seeds by $1 \mathrm{H}$ NMR spectroscopy and multivariate statistical analysis. J. Pharm. Biomed. Anal. 2015, 115, 74-85. [CrossRef]

37. Crawford, R.M. Seasonal differences in plant responses to flooding and anoxia. Can. J. Bot. 2003, 81, 1224-1246. [CrossRef]

38. Hare, P.; Cress, W. Metabolic implications of stress-induced proline accumulation in plants. Plant Growth Regul. 1997, 21, 79-102. [CrossRef]

39. Harbowy, M.E.; Balentine, D.A. Tea chemistry. Crit. Rev. Plant Sci. 1997, 16, 415-480. [CrossRef]

40. Krol, A.; Amarowicz, R.; Weidner, S. The effects of cold stress on the phenolic compounds and antioxidant capacity of grapevine (Vitis vinifera L.) leaves. J. Plant Physiol. 2015, 189, 97-104. [CrossRef]

41. Erturk, Y.; Ercisli, S.; Sengul, M.; Eser, Z.; Haznedar, A.; Turan, M. Seasonal variation of total phenolic, antioxidant activity and minerals in fresh tea shoots (Camellia sinensis var. sinensis). Pak. J. Pharm. Sci. 2010, 23, 69-74.

42. Gololo, S.S.; Shai, L.J.; Agyei, N.M.; Mogale, M.A. Effect of seasonal changes on the quantity of phytochemicals in the leaves of three medicinal plants from Limpopo province, South Africa. J. Pharmacogn. Phytother. 2016, 8, 168-172.

43. Mudau, F.; Soundy, P.; Du Toit, E.; Olivier, J. Variation in polyphenolic content of Athrixia phylicoides (L.) (bush tea) leaves with season and nitrogen application. S. Afr. J. Bot. 2006, 72, 398-402. [CrossRef] 